\title{
Study on the management strategy of Chinese swimming pool based on the security perspective
}

\author{
Ju Xiao ${ }^{1 a}$ Wu Wen ${ }^{2 b}$ \\ ${ }^{1,2}$ Pingxiang University, Jiangxi 337055, China \\ a3423725109@qq.com, b2633241463@qq.com
}

Key words: safety perspective; swimming pool; Countermeasures

\begin{abstract}
: with the improvement of people's living standard, the swimming venue is more and more popular of people, has become an important place for daily leisure. Of course, because the swimming sports itself has a certain risk, must be rational planning of swimming venues and equipment, optimize the management, improve the operation efficiency of the swimming venue security, provide security for the general public in swimming.

Swimming can exercise can make us learn a lot of swimming skills, body fitness, symmetry, cardiopulmonary function, full of go, work efficiency is high; often swimming can improve the body resistance, prevent colds, and the cervical vertebra, lumbar and leg pain and other chronic disease rehabilitation has obvious effect. Swimming has been favored by people of all ages, however, swimming in the water, the water is difficult to avoid accidents. Safety issues related to the swimming pool swimming, swimming enthusiasts, swimming coaches, lifeguards and many other factors, only all aspects of attention swimming safety problems, will it be possible to avoid or reduce the accidents in swimming happen.
\end{abstract}

\section{The requirements of people for the swimming pool}

The swimming venue to talent shows itself in the fierce competition in the market, to meet the people's growing material needs, contribute to the harmonious development of the society, we need to give full consideration to the practical requirements of consumers for the swimming venue. Survey shows that consumer infrastructure in the swimming venue requirements, if in accordance with the degree of attention to sort the words are: water sanitation, safety facilities, ambulance personnel, bathing, dressing, service attitude. In addition, the safety problem of the swimming pool, mainly in two aspects, one is the quality of health problems, the second is the safety equipment and safety and rescue.

\section{Problems in the management of swimming pool}

Swimming as the broad masses of the people really love sports, in recent years in developed markets and the construction of socialist economy tide, toward the direction of professional development, there has been a lot of professional swimming places. But it also faces many problems.

\subsection{Neglect of safety management, lack of legal consciousness}

At present, many swimming venues especially private swimming venues are driven by economic interests to invest a lot of money to buy the safety equipment, safety rescue personnel hiring a professional. In addition, many swimming venues always take chances, to think that people are swimming venues, so many people in the swimming, the accident is not afraid, can to mobilize the masses to help, so a big swimming pool just hired one or two part-time assistant. These do not pay enough attention to safety management, disregard of law behavior, will be in the swimming pool for the daily operation and management exposed security vulnerabilities of the process, once the swimming accident, the consequences be unbearable to contemplate.

\subsection{Lack of a complete business strategy}

The swimming venue and property management goal is different, the swimming venue management diversified characteristics. At present, the main way to swim stadium management 
contract, entrusted with the operation and unit management. The three main business way each has advantages and disadvantages, such as the use of entrusted operation, difficult to effective supervision of the entrusted party the disadvantages of these business. If the managers do not pay attention to the security problems can't be solved effectively, objectively leave hidden dangers to the swimmer, but also to the swimming venue management risk.

\subsection{Hardware facilities backward security}

Our professional swimming venue started late, the hardware facilities are relatively backward. This is mainly manifested in two aspects: first, in the early planning of the swimming pool, a lot of security factors without consideration, especially a lot of swimming venue is converted from other buildings, so the stadium structure, facilities and installation of facilities is relatively backward second, infrastructure; swimming a lot older, the modernization level of deficiencies, such as thermostats, safety early warning system is not obvious, the existing hardware facilities can not fully meet the needs of consumer groups.

\subsection{Loss of the management mechanism of the life buoy}

The lifeguard is the most important part of the safety management system in the swimming pool, is drowning and swimming accident directly involved in the rescue work, so it is very necessary to establish and perfect the swimming pool lifeguard management mechanism. However, the reality is that many professional rescue workers higher wages, some swimming venues will be reduced the number of lifeguards equipped to hire part-time personnel, even undocumented persons posts to save the daily expenses, it is no doubt that the safety of swimmers lay hidden.

\section{Recommendations for the management of the safety of swimming pools}

The swimming venue management should consider the safety of both benefits, in other words, to carry out the operation and management of security benefits based on the idea of course. This is a systematic project, need to play "combined" around "the benefit and safety of both" and people oriented swimming venue management idea, from staff to establish a mechanism of management of the swimming pool.

\subsection{Set up a highly efficient professional management team}

Professional and efficient management team is the premise of swimming venue balance security services and economic benefits. On the one hand, to hire a swimming venue, stadium operations experience of the professionals involved in the day-to-day management of the swimming pool. For example, senior managers in business experience, he should not only understand the basic knowledge of swimming sports, and know how to manage the behavior psychology, so that we can start from the customer's perspective, understand the guests enjoy swimming in the service of the psychological needs; in the service, he should not only have the refined and courteous manner, high cultural accomplishment, but also have a certain psychological quality, still can be in a calm mood in the face of some excited customers to participate in the. Transaction processing. In addition, according to some special management positions, such as emergency management, the staff should have a comprehensive health care knowledge Knowledge, familiar with the safety and rescue skills, but also to their social skills to investigate, to see whether it can maintain good relations with customers.

\subsection{Pay attention to the swimming venues of the media public relations}

For many of the swimming venue despite the good quality of service, the management level is very high, the price is reasonable but due to the lack of market share due to weak operating conditions. On the one hand, the strength of the swimming venue in television, newspapers, magazines and other traditional media on the advertising platform, using the Internet and other new media, increase brand influence and the public awareness, in order to attract people to come to the consumer.

\subsection{Improvement of the management mechanism of the life buoy}

As the swimming pool, to strengthen the occupation moral education the lifeguard organization, the lifeguard to watch video, to a higher level of swimming venue to visit and study, improve their professional quality and excellent quality, the only way to ensure that relief workers in their jobs do 
diligence and responsibility, customer swimming venue personal safety can be guaranteed. In addition to the necessary lifeguard rescue operation ability, should also have a higher personal accomplishment and service consciousness. Through competition can help to build a swimming pool as soon as possible professional hard, high personal qualities, strong sense of service of the rescue team.

\subsection{Increase the swimming pool safety infrastructure}

In the daily operation of the process, should pay attention to the safety of facilities maintenance work, timely update, ensure the safety of facilities in the process of using the real protection of swimming personnel security role. Investors should be rational use of financial leverage, attracting strategic investment, the introduction of advanced technology and equipment, eliminate backward production capacity, which can reduce the operation cost for the equipment. Aging or backward equipment, must be determined to improve, not only can short-term benefits while ignoring the long-term interests.

\subsection{Completes the swimming pool safety accident emergency plan}

The swimming venue should advance to establish corresponding emergency plans and accidents, so once the customer drowning danger, rescue personnel can save customers everything in good order and well arranged, the loss of life and property to the maximum extent. Under certain conditions, the museum in the swimming pool to install monitoring system, the implementation of dual control, the main venue to rescue staff visits, off camera video surveillance. At the same time also need to send the alarm system with warning function as auxiliary equipment of lifeguards, reduce accidents.

\section{Summary}

The swimming venue and people's entertainment life, how to ensure the maximum degree of economic benefits under the premise of the personal safety of customers, promote the long-term development of the swimming pool, we need to constantly practice and exploration. The swimming venue safety management is a long-term and systematic project, need the government and the whole society to care and support, actively absorb and learn from the successful experience of foreign countries, swimming venues safety management reform and innovation, pay attention to the rational allocation of social resources and utilization, to explore suitable for China's "anti drowning disaster" safety management system, to create a safe environment for swimming good for consumers to achieve the harmony between man and nature.

\section{Acknowledgments:}

Draft date: $2016-10-1$

Fund project: Science and technology project in jiangxi province department of education 《Study on the construction of swimming pool safety assessment model》

\section{Reference}

[1]Fan Zhang. Analysis and Study on the current situation of the safety and security of swimming pool in Taiyuan city [D]. Shanxi Normal University, 2012

[2]Jin-Bo Gu. Research on the status quo of children's swimming activities in Wuhou District, Chengdu [D]. Chengdu Sport University, 2007

[3]Xin Zhang. Study on the influence factors and Countermeasures of the safety factors and Countermeasures of the public swimming training class in Beijing [D]. Beijing Sport University, 2012

[4]Shun-Chuan Liu. Study on the safety and security of swimming pool in South of Jiangsu area [D]. Beijing: Beijing Sport University, 2008 
[5]Ling Jiang et al. Research on the Countermeasures of preventing and reducing swimming accidents [J]. sports science, 2004 (8) 